\title{
Effects of Squatting with Different Foot Positions on Muscle Activations in Subjects with Genu Varum
}

\author{
JoonHo Seo ${ }^{1}$, JongSung Chang ${ }^{2}$, MiYoung Lee ${ }^{3}$ \\ 'Department of Medical Science, Graduate School, Daegu Haany University; ${ }^{2}$ Department of Physical Therapy, Yeungnam University College; \\ ${ }^{3}$ Department of Physical Therapy, College of biomedical Science, Daegu Haany University, Gyeongsan, Korea
}

Purpose: This study examined the effects of squatting with different foot positions on the muscle activation of the vastus medialis oblique (VMO) and vastus lateralis (VL) muscles in subjects with genu varum.

Methods: Thirty four subjects participated in this study. Surface electromyography was used to measure the muscle activation of the VMO and VL muscles at the knee angles $\left(15^{\circ}, 60^{\circ}\right)$ at three foot positions (internal rotation, neutral position, external rotation) during squatting.

Results: Muscle activation differences at different knee angles and foot positions differed significantly between the VMO and VL muscles in both the varus and normal groups. In addition, there was a significant difference according to the knee angles with the foot in external rotation in the VMO and VL ratio. In the varus group, however, the VMO and VL ratio were significantly different only with the feet in internal rotation. In the muscle activation changes of the knee angle differences in the foot position, there was no significant difference in the varus group, but both the VMO and VL muscles were significant different in the normal group.

Conclusion: In both groups, regardless of the foot position, muscle activation of the VMO and VL muscles increased with increasing knee flexion angle. In the normal group, when squatting with the feet in external rotation, the VMO and VL muscles activations increased with increasing knee angle. In the varus group, however, the foot position did not affect the VMO or VL muscle activation. This study shows that subjects with genu varum and normal subjects have different VMO and VL muscle activation patterns during squat exercises.

Keywords: Electromyography, Genu varum, Muscle activation, Squat

\section{서 론}

한국사회에서는 무릎관절 부정정렬을 서양에서보다 쉽게 볼 수 있 는데, 이는 어려서부터 두꺼운 기저귀의 장시간 착용, 오랫동안 업어 키운 경우, 좌식 생활로 인해 다리를 벌리고 앉는 습관 등이 한국인 들의 무릎관절 부정정렬에 영향을 미친 것으로 보고 되어진다.1-3 정 상적인 무릎관절은 외부로부터 오는 충격을 흡수, 완화하며 보행 시 빠른 무릎 굽힘을 통하여 넙다리네갈래근의 근길이를 적절히 조절하 게 해준다. 정상적인 무릎 정렬은 똑바로 선 자세를 관상면에서 보았 을 때 넙다리뼈 머리의 중심에서부터 목말뼈의 위쪽 관절면의 중심 까지 그려지는 선이 무릎 중심을 통과하거나 중심과 매우 가까운 곳 을 통과한다.5 하지만, 이러한 정상적인 정렬을 벗어나게 되는 것을 무 릎의 부정정렬이라고 일컫는다. 무릎관절에서의 부정정렬은 크게 안

Received Mar 18, 2019 Revised Apr 17,2019

Accepted Apr 28, 2019

Corresponding author MiYoung Lee

E-mail mykawai@hanmail.net
굽이무릎과 밖굽이무릎으로 두 가지로 나뉘어 지는데, 넙다리네갈 래근각(Q-angle)에 의해 평균 170-175넙다리네갈래근각을 정상 기 준으로 이보다 각도가 크면 안굽이무릎, 각도가 작으면 밖굽이무릎 으로 분류한다.1.5,6

특히, 안굽이무릎의 경우 정상적인 넙다리뼈 융기사이패임과 정강 뼈융기사이결절을 이은 선인 하지의 기능 축에서 무릎관절 중심이 바깥쪽으로 10-20 mm 이동되어 있으며, 흔히 ' $\mathrm{O}$ 다리로 널리 알려져 있다. 안굽이무릎이 심해질 경우 정상적인 Q각의 부정정렬으로 인 해 무릎관절의 안쪽반달연골에만 하중이 집중되게 되어 퇴행성관 절염을 발생시키는 요인이 되고, 신체의 기능을 저하시키는 주요한 원인이 된다. ${ }^{78}$ 또한 안굽이무릎을 가진 사람들에게서 정강빼의 안 쪽돌림, 발가락의 가쪽돌림을 관찰할 수 있는데,' 이로 인해 보행 시 양 발을 많이 벌리고 발가락이 안쪽을 향하는 안짱걸음(pigeon toe 
gait)이 나타나거나, 체중이 바깥쪽으로 치우치게 되어 오리걸음(waddling gait)이 나타날수 있다.,9

한편, 스쿼트 동작은 엉덩관절, 무릎관절, 발목관절에서 움직임이 나타나는 복합관절의 닫힌사슬 운동으로서 다수의 근육군들이 동 시에 협응하여 동작이 일어난다. ${ }^{10,11}$ 스쿼트 동작 시 활성화되는 근육 들은 엉덩이, 넙다리네갈래근, 몸통 근육으로, 무릎 재활에 흔히 사 용되는 운동 방법이다. ${ }^{12}$ 하지만 안굽이무릎을 가진 사람들이 스쿼 트 동작 시 하지의 부정정렬으로 인해 안쪽넓은근과 가쪽넓은근에 적절한 자극이 주어지지 않으면 잘못된 자세를 유발하게 되고 좌우 비대칭을 더욱 증가시키며 자칫하면 상해로 이어질 수 있다.10,12 또한, Park 등13은 안굽이무릎을 가진 사람들을 대상으로 근활성화를 통 한 개시시간 차이에 대한 연구를 통해 대상자들에게서 안쪽넓은근 보다 가쪽넓은근의 개시시간이 늦게 나타나는 것을 보고하였다. 이 는 안굽이무릎을 가진 대상자에서 선택적인 넙다리네갈래근의 운 동이 필요함을 시사할수 있다.

따라서 본 연구는 안굽이무릎을 가진 정상인에서 다양한 발의 위치 에서 스쿼트 동작 시 무릎 각도에 따른 근활성화에 대해 알아보았다.

\section{연구 방법}

\section{1. 연구대상}

연구대상자는 신경학적 증상이 없고, 근골격계의 질환 병력이 없는 건강한 성인 34 명이 참여하였으며 무릎 간 간격(intercondylar distance, IC)과 발목 간 간격(intermalleolar distance, IM)에 의해 안굽이 무릎군 17 명(남성 8 명, 여성 9명)과 정상군 17 명(남성 10 명, 여성 7 명) 으로 분류하였다. 안굽이 무릎군의 선정 기준은 무릎 간 간격이 $4 \mathrm{~cm}$ 이상인 자, 발목간 간격이 $4 \mathrm{~cm}$ 미만 인 자로 선정하였다. ${ }^{14}$ 무릎 간 간 격은 줄자를 사용하여 대상자가 똑바로 섰을 때 무릎 관절융기사이 거리를 측정하였고, 발목 간 간격은 줄자를 사용하여 대상자가 똑바 로 섰을 때 왼쪽과 오른쪽 안쪽 복사뼈의 거리를 측정하였다. 실험에 앞서 모든 연구상자에게 연구의 목적 및 취지를 설명하고 자발적인 동의를 얻은 후 본 실험을 시행하였다.

\section{2. 실험절차}

\section{1) 근활성화 측정}

대상자들에게 세 가지 발의 위치(안쪽돌림, 중립, 가쪽돌림)에서 두 가지 무릎 각도 $\left(15^{\circ}\right.$ 와 $\left.60^{\circ}\right)$ 의 스쿼트 동작을 적용하여 오른쪽 하지의 안쪽넓은근과 가쪽넓은근의 근활성화를 측정하였다. 스쿼트의 무 릎 각도는 측각기(Goniometer, Baseline ${ }^{\circledR}$ Absolute+Axis ${ }^{\circledR}$ Goniometers, USA)를 이용하여 각각 $15^{\circ}$ 와 $60^{\circ}$ 로 설정하였다. 대상자의 무릎 바깥 쪽에 측각기를 위치시키고 고정팔은 종아리뼈의 장축과 평행하게 위
치시켰고 측정팔은 넙다리뼈 장축에 평행하도록 위치시켰다. 각 각도 에서 스쿼트를 시행하기 전 세 가지 발의 위치를 설정한 후 스쿼트 동 작을 시행하였고 발의 위치 별 각 무릎 관절 각도에서 안쪽넓은근과 가쪽넓은근의 근활성화를 측정하였다. 세 가지 발의 위치에서 중립 은 발꿈치뼈의 중심과 두 번째 발가락 사이를 일직선으로 지나가는 선과 평행한 선으로 정의하였고, 안쪽돌림은 발의 중립 위치를 기준 으로 안쪽으로 $30^{\circ}$ 모음 위치, 가쪽돌림은 발의 중립 위치를 기준으로 바깥쪽으로 $30^{\circ}$ 벌림 위치로 정의하였다. ${ }^{16}$ 각도와 발의 위치에 따른 순서의 효과를 배제하기 위해 무작위로 실시하였다. 각 발의 위치에 서 두 가지 무릎 각도의 스쿼트 동작자세에 대한 설명을 들은 충분한 연습을 통해 익숙해진 후 본 실험의 측정을 시작하였다. 발의 위치 별 스쿼트 동작 시 각 무릎 굽힘 각도 $\left(15^{\circ}\right.$ 와 $\left.60^{\circ}\right)$ 에서 근활성화를 6 초 동 안 측정하고 3 번 반복하였다. 근피로 방지를 위해 측정 간 1 분의 휴식 시간을 가졌고, 6 초 간 수집된 데이터 중 처음과 끝의 1.5 초를 제외한 중간의 3 초를 분석에 사용하였다. 수집된 표면 근전도 신호는 Telemyo DTS로 보내져 디지털 신호로 전환한 뒤 MR 3.6 (Noraxon, USA) 소프트웨어를 사용해 필터링과 기타 신호처리 하였다.

\section{3. 측정도구}

\section{1) 표면 근전도(surface electromyograph)}

안쪽넓은근과 가쪽넓은근의 근활성화를 측정하기 위해 무선 근전 도 측정기인 Telemyo DTS, desk receiver (NORAXON, USA)를 사용하 여 측정하였다. 본 연구에서 사용한 표면근전도 신호는 표본추출률 (sampling rate) 1,000 Hz, 대역통과 필터링(Bandpass filter) 20-450 Hz로 설정하였고, 노치 필터(notch filter)는 $60 \mathrm{~Hz}$ 로 설정하였다. 대역통과 필터링(Bandpass filter)을 한 후 정류(retification)하였고, 평균제곱근 (root mean square, RMS)를 적용하여 고르지 못한 정류 파형을 부드럽 게 만들었다. 그 후 최대 등척성 수축값(\%maximal voluntary isometric contraction, \%MVIC)으로 정량화(normalization)하였다.

본 연구에서는 근 수축을 표준화하는 방법으로 $\% \mathrm{MVIC}$ 를 사용하 여 처리하였다. 최대 등척성 수축값을 측정하는 방법으로 탄력 밴드 (Thera-Band ${ }^{\mathrm{TM}}$, THERABAND ACADEMY, APTA, USA) 4단계 파랑 색을 사용하였다. 실험 시작 전 MVIC 측정을 위해 엉덩관절과 무릎 관절 모두 $90^{\circ}$ 로 설정하고 의자에 앉았다. 의자에 앉았을 때 등받이 에 등을 기대지 않도록 지시하였다. 발목관절 가쪽복사뼈 위 $5 \mathrm{~cm}$ 지 점에 탄력 밴드를 묶고 다른 한 쪽은 테이블 기둥에 묶었다. 대상자에 게 시작! 이라고 말하면 무릎을 끝까지 쭉 펴세요.' 라고 구두 지시하 였고 최대 등척성 수축을 시킨 후 평균값의 오차를 줄이기 위해 6초 간 수축한 값의 처음 1.5 초와 마지막 1.5 초를 제외한 3 초의 평균값을 최대 등척성 수축값으로 정하였다. 대상자가 최대 수축을 유도할 수 있도록 구두 지시를 통하여 격려하였다. 


\section{2) 전극 부착}

표면 전극 $(\mathrm{Ag} / \mathrm{AgCl} 2223,3 \mathrm{M}$, Korea)은 지름 $3 \mathrm{~cm}$ 의 일회용 접착 전극 을 사용하였다. 전극 부착 전 대상자들의 측정할 다리의 안쪽넓은근 과 가쪽넓은근 부위에 털을 면도기로 제거한 후 알코올 솜으로 깨끗 이 닦은 후 전극을 부착하였다. 전극 부착 부위는 넙다리뼈의 장축을 기준으로 $50^{\circ}$, 무릎뼈 바닥에서 위안쪽 $5 \mathrm{~cm}$ 지점을 안쪽넓은근으로 표시하여 부착하였고, 가쪽넓은근의 경우 무릎뼈 바닥을 기준으로 5 $\mathrm{cm}$ 위가쪽, 넙다리뼈 장축으로부터 $15^{\circ}$ 바깥쪽을 측정하여 점으로 표시한 후참고하여 대상자에게 무릎을 힘껏 펴 보라고 한 후 근복이 최대로 두드러지는 곳에 안쪽넓은근과 가쪽넓은근의 활성 전극을 부착하였다. ${ }^{13}$ 접지전극은 정강뼈결절 부근에 부착하였다..$^{13}$

\section{4. 자료 분석}

데이터는 Kolmogorov-Smirnov test에 의한 정규성 검정을 실시한 결 과 가정에 만족하여, 모수 검정을 사용하였다. 집단 간 동질성 차이를 알아보기 위해 독립표본 검정(independent t-test)를 사용하였다. 집단 내 발의 안쪽 돌림, 중립, 가쪽 돌림에서 무릎 굽힘 각도 $\left(15^{\circ}\right.$ 와 $\left.60^{\circ}\right)$ 별 근활성도 비교를 위해 짝비교 검정(paired t-test)을 사용하였다. 또한 발의 위치에 따른 근활성화의 무릎 각도 차이의 변화량 $\left(60^{\circ}-15^{\circ}\right)$ 을 비 교하기 위해 일요인 분산분석(one-way ANOVA)를 사용하였다. 검정 결과 유의한 차이가 있을 경우 대비 검정을 사용하여 발의 위치 간 차이를 알아보았다. 통계 처리를 위해 SPSS ver. $12.0 \mathrm{~K}$ for window를 사
용하였고, 유의수준 $\alpha=0.05$ 로 설정하였다.

\section{결 과}

\section{1. 연구대상자의 일반적 특성}

연구 대상자의 일반적인 특성은 Table 1과 같다. 그룹간에서 나이, 키, 발목 간 간격은 유의한 차이가 없었고 $(\mathrm{p}>0.05)$, 무릎 간 간격에서 유 의한차이를 보였다 $(\mathrm{p}<0.05)($ Table 1$)$.

\section{2. 각 발의 위치에서의 무릎 관절 각도에 따른 근활성도 차이}

안굽이 무릎군과 정상군 모두 안쪽넓은근과 가쪽넓은근에서 각 발 의 위치에서 무릎 각도에 따른 근활성도는 유의한 차이가 있었다 $(\mathrm{p}<0.05)$. 또한 안쪽넓은근과 가쪽넓은근의 비율에서 발의 위치가 중

Table 1. general characteristics of subjects.

$(n=34)$

\begin{tabular}{lccc}
\hline & Genu varum group & Normal group & $\mathrm{p}$ \\
\hline Gender (M/F) & $8 / 9$ & $10 / 7$ & 0.90 \\
Age (year) & $22.06 \pm 1.48^{\mathrm{a}}$ & $21.18 \pm 1.47$ & 0.90 \\
Height (cm) & $169.35 \pm 8.52$ & $169.53 \pm 7.80$ & 0.95 \\
Weight (kg) & $61.71 \pm 11.79$ & $65.59 \pm 11.40$ & 0.34 \\
IC (cm) & $5.68 \pm 0.95$ & $1.83 \pm 1.33$ & $0.00^{*}$ \\
IM (cm) & $2.19 \pm 0.54$ & $2.10 \pm 1.09$ & 0.77 \\
\hline
\end{tabular}

amean \pm SD, IC: intercondylar distance, IM: intermalleolar distance, *statically significant $(p<0.05)$.

Table 2. Differences in muscle activities at different knee angles and foot positions

(Unit: \%MVIC)

\begin{tabular}{|c|c|c|c|c|c|}
\hline \multirow{2}{*}{ Group } & \multirow{2}{*}{ Muscle } & \multirow{2}{*}{ Foot Position } & \multicolumn{2}{|c|}{ Knee Angle } & \multirow{2}{*}{$p$} \\
\hline & & & $15^{\circ}$ & $60^{\circ}$ & \\
\hline \multirow[t]{9}{*}{ Genu varum group } & VMO & Int & $13.22 \pm 8.18$ & $34.48 \pm 13.08$ & $0.000^{*}$ \\
\hline & & Neut & $11.81 \pm 5.90$ & $38.07 \pm 15.25$ & $0.000^{*}$ \\
\hline & & Ext & $12.76 \pm 9.30$ & $39.43 \pm 17.25$ & $0.000^{*}$ \\
\hline & $V L$ & Int & $12.55 \pm 6.03$ & $30.55 \pm 14.77$ & $0.000^{*}$ \\
\hline & & Neut & $10.48 \pm 4.91$ & $32.04 \pm 16.32$ & $0.000^{*}$ \\
\hline & & Ext & $12.12 \pm 7.06$ & $32.75 \pm 12.61$ & $0.000^{*}$ \\
\hline & VMO:VL & Int & $1.03 \pm 0.30$ & $1.20 \pm 0.44$ & $0.031^{*}$ \\
\hline & & Neut & $1.18 \pm 0.49$ & $1.29 \pm 0.50$ & 0.201 \\
\hline & & Ext & $1.04 \pm 0.38$ & $1.25 \pm 0.46$ & $0.019^{*}$ \\
\hline \multirow[t]{9}{*}{ Normal group } & VMO & Int & $12.58 \pm 4.33$ & $38.28 \pm 15.85$ & $0.000^{*}$ \\
\hline & & Neut & $11.31 \pm 5.16$ & $42.72 \pm 18.12$ & $0.000^{*}$ \\
\hline & & Ext & $10.57 \pm 4.79$ & $44.08 \pm 18.21$ & $0.000^{*}$ \\
\hline & $\mathrm{VL}$ & Int & $13.25 \pm 6.19$ & $36.87 \pm 19.49$ & $0.000^{*}$ \\
\hline & & Neut & $12.34 \pm 5.50$ & $39.85 \pm 20.53$ & $0.000^{*}$ \\
\hline & & Ext & $11.86 \pm 7.2$ & $41.53 \pm 21.88$ & $0.000^{*}$ \\
\hline & VMO:VL & Int & $1.05 \pm 0.41$ & $1.13 \pm 0.34$ & 0.405 \\
\hline & & Neut & $1.00 \pm 0.50$ & $1.15 \pm 0.38$ & 0.247 \\
\hline & & Ext & $0.96 \pm 0.35$ & $1.18 \pm 0.37$ & $0.040^{*}$ \\
\hline
\end{tabular}

*Statically significant $(\mathrm{p}<0.05)$, VMO: vastus medialis oblique, VL: vastus lateralis, VMO: VL: ratio of VMO \& VL, Int: foot $30^{\circ}$ internal rotation, Neut: foot parallel to sagittal plane, Ext: foot $30^{\circ}$ external rotation. 

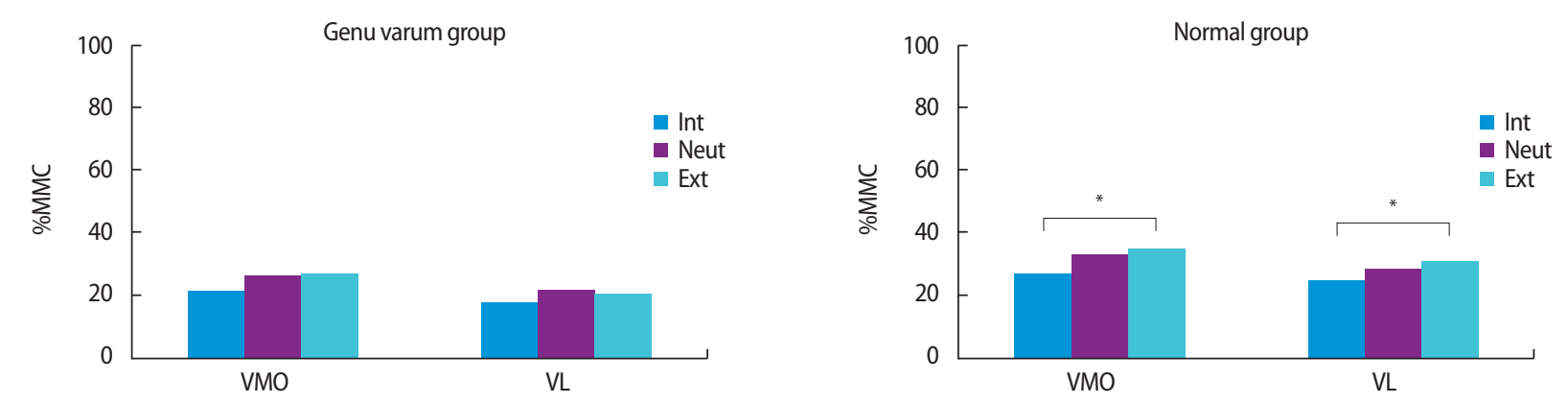

Figure 1. The difference according to the foot position for variation of muscle activity between the different knee angles $\left(60^{\circ}-15^{\circ}\right)$ in each muscle. ${ }^{*}$ Repeated measured ANOVA for VMO and VL muscle activation according to foot position, $p<0.05$.

립위치에서는 두 집단 모두 무릎각도에 따라 유의한 차이가 없었으 나( $\mathrm{p}>0.05)$, 가쪽돌림에서는 무릎각도에 따라 유의한 차이가 있었다 $(\mathrm{p}<0.05)$. 발의 위치가 안쪽돌림에서 안굽이무릎군은 무릎각도에 따 라 유의한 차이가 있었던 $(\mathrm{p}<0.05)$ 반면 정상군은 유의한 차이가 없었 다( $>0.05)$ (Table 2).

\section{3. 발의 위치에 따른 무릎 관절 각도 차이에서의 근활성도 변화량의 차이}

무릎 관절 각도 차이 $\left(60^{\circ}-15^{\circ}\right)$ 의 근활성도 변화량에 대해 안굽이무릎 군은 발 위치에 따라 안쪽넓은근과 가쪽넓은근 모두에서 유의한 차이 를 나타내지 않았다( $\mathrm{p}>0.05)$. 하지만 정상군에서는 발 위치에 따라 안 쪽넓은근과 가쪽넓은근 모두에서 유의한차이를 보였는데 $(\mathrm{p}<0.05)$, 대 비검정 결과 안쪽넓은근과 가쪽넓은근 모두 발의 위치가 안쪽돌림과 가쪽돌림 사이에서 유의한 차이를 보였다( $<<0.05$ )(Figure 1).

\section{고 찰}

본 연구는 무릎관절 부정정렬을 가진 대상자에서 다양한 발의 위치 에서 스쿼트 동작을 수행 시 안쪽넓은근과 가쪽넓은근의 활성도를 측정하였다. 연구 결과 두 집단 모두 세 가지 발의 위치에서 무릎 각 도가 $15^{\circ}$ 에서 $60^{\circ}$ 로 증가할수록 안쪽넓은근과 가쪽넓은근 모두에서 활성화가 유의한 증가를 나타내었다. 하지만 안쪽넓은근과 가쪽넓은 근의 활성화 비에서는 안굽이 무릎군이 발의 위치가 안쪽 돌림과 가 쪽돌림에서 유의한 차이를 보인 반면 정상군에서는 가쪽돌림에서만 유의한 차이를 보였다. 무릎관절 각도 차이의 근활성도 변화값 $\left(60^{\circ}\right.$ $\left.-15^{\circ}\right)$ 에 대한 발의 위치에 따른 차이를 보았을 때 안굽이무릎군은 발 의 위치에 따라 안쪽넓은근과 가쪽넓은근 모두에서 유의한 차이를 나타내지 않았다. 하지만 정상군에서는 안쪽넓은근과 가쪽넓은근 모두에서 유의한 차이를 보였고 특히, 안쪽돌림과 가쪽돌림 사이에 서 유의한 차이를 나타내었다. 따라서 모든 그룹에서 무릎 굽힘 각도 를 증가시킬수록 안쪽넓은근과 가쪽넓은근의 근활성화가 크게 나타
났다. 하지만, 안쪽돌림 위치에서 안쪽넓은근과 가쪽넓은근의 활성 화 비에 대한 무릎 각도 차이와 두 무릎관절 각도의 근활성화 변화값 에 대한 발 위치의 차이에서는 안굽이무릎군이 정상인과 다른 결과 양상을 볼수 있었다.

안굽이무릎은 넙다리뼈의 안쪽 돌림, 양발의 뒤침, 무릎의 과다폄 이 복합적으로 나타나 발생하고 이차적으로 척추변형, 요통과 같은 척추와 골반의 전반적인 퇴행과 다리 정렬의 변형으로 인하여 무릎 관절염 및 허리 추간판탈출증과 같은 문제를 일으킬 수 있다. ${ }^{2,318}$ 선 행 연구로 스쿼트 동작 시 안쪽넓은근과 가쪽넓은근의 근활성화에 대한 연구들이 많이 보고 되었다. ${ }^{16,19,20} \mathrm{Jang}$ 등 16 은 편마비 환자의 마 비측과 비마비측 안쪽넓은근과 가쪽넓은근를 일반적인 스쿼트 동 작 시 무릎 굽힘 각도에 따른 근활성화를 비교하였는데 그 결과마비 측과 비마비측 모두 각 발의 위치에서 무릎 굽힘 각도가 증가할수록 안쪽넓은근과 가쪽넓은근 모두에서 근활성화가 유의하게 증가하였 다고 보고하였다. 같은 해 Kim과 Song ${ }^{20}$ 의 연구에서 20대 건강한 여 성 12 명에게 세 가지 발의 위치에서 세 가지 무릎 각도 별 안쪽넓은근 과 가쪽넓은근의 근활성화를 측정한 결과 안쪽넓은근과 가쪽넓은 근 모두 무릎 각도가 증가할수록 근활성화가 유의하게 증가하였고, 발의 위치 및 발의 위치와 무릎각도 간의 상관관계도 나타났다. 본 연 구에서도 정상군 뿐만 아니라 안굽이무릎군에서도 모든 발의 위치 (안쪽, 중립, 바깥쪽)에서 무릎 굽힘 각도의 증가에 따라 안쪽넓은근 과 가쪽넓은근의 근활성도가 유의하게 증가되었다는 것과 동일하게 나타나고 있다.

중립 발의 위치에서 스쿼트 동작시 정상인의 가쪽넓은근에 대한 안쪽넓은근의 비율은 약 $1: 1$ 로 나타나는데, 가쪽넓은근에 대한 안쪽 넓은근의 근활성비가 1 보다 큰 것은 안쪽넓은근이 가쪽넓은근 보다 활성이 큰 것을 나타낸다. ${ }^{20,21}$ 더불어 몇몇 연구에서는 안굽이무릎을 가진 사람들은 다리 변형으로 넙다리네갈래근, 특히 안쪽넓은근과 큰모음근과 같은 안쪽 연부조직의 단축과 넙다리근막긴장근과 넙치 근과 같은 바깥쪽 연부조직의 이완된 양상을 보인다고 보고하였 다.1,3,18,22 본 연구에서는 가쪽넓은근에 대한 안쪽넓은근의 활성화 비 
의 무릎각도별 비교 시 정상군에서 발의 위치가 중립과 안쪽돌림 시 유의한 차이를 나타내지 않았는데 반해 안굽이무릎군에서 발의 위 치가 안쪽돌림 시 유의한차이를 나타내었다. 이는 안굽이 무릎을 가 진 대상자들의 넙다리뼈가 정강뼈에 비해 상대적으로 가쪽 돌림되 어 발의 위치를 안쪽 돌림 할 시 넙다리뼈의 모음으로 인하여 엉덩관 절 모음이 유발되는데 안쪽빗넓은근이 큰모음근의 먼쪽 부분에 위 치하여 엉덩관절 모음 시 안쪽넓은근의 근활성화에 유의한 차이가 나타난 것으로 사료된다. ${ }^{23}$ 따라서, 안굽이 무릎을 가진 대상자에서 발을 안쪽 돌림하여 스쿼트 동작을 할 경우 무릎 각도가 증가할수록 안쪽넓은근과 가쪽넓은근의 활성화의 불균형 정도가 정상인과 비교 하여 증가함을 알 수 있다.

선행연구에서는 특정 대상자들에서 발의 위치에 따른 무릎근육 의 활성화를 조사하여 다양한 결과를 보고하였는데, Yoo 등19는 무 릎넙다리통증증후군을 가진 환자에게 양 발을 어깨넓이의 $120 \%$ 로 벌린 자세에서 엉덩관절 $20^{\circ}$, 발의 $20^{\circ}$ 모음, 무릎을 $45^{\circ}$ 굽힘의 스쿼트 동작에서 안쪽넓은근과 가쪽넓은근의 높은 근활성도를 보였다. 또 한 Jang 등 16 은 편마비 환자에게 발의 위치에 따른 안쪽넓은근과 가쪽 넓은근의 근활성화를 평가하였는데 발의 위치는 안쪽넓은근과 가 쪽넓은근의 근활성화에 영향을 미치지 않았다고 보고하였다. 본 연 구에서는 무릎각도 차이에 대한 안쪽넓은근과 가쪽넓은근의 활성 도 변화량을 발 위치에 따라 비교해 보았을 때 안굽이무릎군에서 세 발의 위치 간 유의한 차이를 나타내지 않았지만 정상군의 경우 발의 위치에 따라 근활성화에 차이를 보였다. Signorile 등 24 는 발의 위치가 정강이뼈의 돌림을 유발하여 넙다리네갈래근 각 $(\mathrm{Q}$ angle)의 변화를 일으켜 넙다리네갈래근 운동 시 영향을 미칠 수 있다고 보고 하였는 데 안굽이 무릎의 경우에는 부정정렬로 인한 역학적인 변화로 정상 군과는 다른 근활성화 양상을 보인 것으로 생각된다. 따라서, 본 연구 의 결과로 알 수 있듯이 안굽이무릎군의 경우 발의 위치가 근활성화 변화량에 영향을 미치지 않지만 정상인의 경우, 발의 위치를 가쪽돌 림하여 스쿼트를 적용할 시 무릎각도가 증가할수록 안쪽넓은근과 가쪽넓은근의 더 큰 활성화를 야기할 수 있을 것으로 생각된다.

본 연구에서는 안굽이무릎을 가진 사람들의 올바른 운동 프로그 램을 설정하기 위해 안굽이무릎을 가진 대상자에서 다양한 발의 위 치에서 스쿼트 동작 시 무릎 각도 별 근활성화에 대해 알아보았다. 그 결과, 안굽이 무릎을 가진 대상자는 스쿼트 동작 시 정상인과는 일 부 다른 양상을 보였다. 따라서 안굽이 무릎을 가진 대상자가 하지 근력운동으로 많이 사용되고 있는 스쿼트 동작 훈련을 할 때에 균형 잡힌 안쪽넓은근과 가쪽넓은근의 발달에 초점을 맞추어 스쿼트 동 작의 발의 위치와 각도를 적용해야 할 것이다. 하지만 본 연구에서는 대부분 20대의 경도 안굽이 무릎을 가진 대상자로 전반적인 안굽이 무릎을 가진 대상자의 특성을 충분히 반영하지 못하였다고 사료된
다. 따라서 추후에는 다양한 스쿼트 동작에 대한 동작분석학적 연구 를 통하여 다양한 연령대의 안굽이 무릎을 가진 대상자의 적절한 운 동 프로그램의 개발과 중재를 통한 치료 효과에 대한 연구가 필요할 것으로 생각된다.

\section{REFERENCES}

1. Park JH. Therapeutic exercise for musculoskeletal system. Seoul, Panmun education. 2017:541.

2. Han SM, Lee KK, Ha S et al. The effects of correction exercise on hip joint angle, $\mathrm{Q}$ angle, and the distance between knees of genu varum patients. A J Kinesiol. 2010;13(1):83-90.

3. Jeong JM, Lim BO. Differences of lower extremity muscle activities between genu varum females and straight-leg females in squat. Journal of Korean Association of Physical Education and Sport for Girls and Women. 2016;30(4):387-97.

4. Lee NK, Kim YM, Kim K. Influence of unilateral muscle fatigue in knee and ankle joint on balance and gait in healthy adults. J Kor Phys Ther. 2017;29(1):39-43.

5. Neumann DA. Kinesiology of the musculoskeletal system: foundations for rehabilitation. St Louis, Mosby, 2010.

6. Chae YW, Park JW, Park S. The effect of postural stability on genu varum in young adults. J Kor Phys Ther. 2012;24(6):419-22.

7. Chae YW, Park JW, Park S. Effects of knee malalignment on static and dynamic postural stability. J Kor Phys Ther. 2015;27(1):7-11.

8. Chae YW, Park S, Park JW. Pelvic, hip, and knee kinematics of stair climbing in people with genu varum. J Kor Phys Ther. 2018;30(1):14-22.

9. Moon MS, Lee IJ, Chang H. Rachitic bow leg deformity. J of Korean Orthop Asso. 1982;17(3):429-37.

10. Hyeon DS. The effect of different leg positions during squat performance on power expression of spinal and lower extremities in elite weight lifters. Korea National Sport University. Dissertation of Master's Degree. 2013.

11. Shon JW, Lim HW. Comparison of muscle activities of trunk and lower limb during bow and squat exercises. J Kor Phys Ther. 2016;28(2):95100.

12. Kim WG, Kim YS, Kim YB et al. Effects of fast treadmill training on spinal alignment and muscles thickness. J Kor Phys Ther. 2017;29(4):17580

13. Park S, Lee WJ, Park JW. Differences of onset timing between vastus medialis and lateralis during knee isometric contraction on individuals with genu varum or valgum. J Kor Phys Ther. 2014;26(1):9-14.

14. Kang SH, Lee WJ, Kim TY. Possible effects of applying rehabilitation program upon bowlegged undergraduates' COG(center of gravity) oscillation and its correction. Journal of Sport. 2009;35:1061-72

15. Escamilla RF. Knee biomechanics of the dynamic squat exercise. Med Sci Sports Exerc. 2001;33(1):127-41.

16. Jang JH, Kim KH, Kim TH et al. The effects of foot and knee position on electromyographic activity of the vastus medialis and vastus lateralis for hemiplegic patients. J Kor Phys Ther. 2010;22(4):21-8.

17. Cowan SM, Bennell KL, Hodges PW et al. Delayed onset of electromyographic activity of vastus medialis obliquus relative to vastus lateralis in 
subjects with patellofemoral pain syndrome. Arch Phys Med Rehabil. 2001;82(2):183-9.

18. Cook G, Burton L, Kiesel K et al. Movement: functional movement systems: screening, assessment, and corrective strategies. Aptos, OTP, 2011.

19. Yoo WG, Yi CH, Lee HJ. Effects of a combined posture of the lower extremity on activity of the vastus medialis oblique muscle and vastus lateralis muscle during static squat exercise. Phys Ther Korea. 2004;11(3):19.

20. Kim HH, Song CH. Effects of knee and foot position on emg activity and ratio of thevastus medialis oblique and vastus lateralis during squat exercise. J Muscle Joint Health. 2010;17(2):142-50.

21. Souza DR, Gross MT. Comparison of vastus medialis obliquus: vastus lateralis muscle integrated electromyographic ratios between healthy subjects and patients with patellofemoral pain. Phys Ther. 1991;71(4):310-6.

22. Moon SG. The influence of the genu varum and the genu valgum on malalignment of the lower limb. J Korean Acad Orthop Man Phys Ther. 2000;6(2):31-8.

23. Bose K, Kanagasuntheram R, Osman M. Vastus medialis oblique: An anatomic and physiologic study. Orthopedics. 1980;3(9):880-3.

24. Signorile JF, Kwiatkowski K, Caruso JF et al. Effect of foot position on the electromyographical activity of the superficial quadriceps muscles during the parallel squat and knee extension. The Journal of Strength \& Conditioning Research. 1995;9(3):182-7. 